\title{
Reflecting on my Assumptions and the Realities of Arts-Based Participatory Research in an Integrated Dance Community
}

\author{
Kelsie Acton
}

ABSTRACT The arts-based research paradigm prioritizes creativity, relationships and the potential of transformative change (Conrad \& Beck, 2016). Arts-based research may be useful in disability communities where people may prefer to communicate artistically or through movement, rather than through spoken word (Eales \& Peers, 2016). Participatory action research (PAR) involves researchers working with communities to create research critical of dominant power relations and responsive to the needs of communities (McIntyre, 2008). Both arts-based research and PAR value an axiological approach that is responsive to the community's needs over a dogmatic procedure, meaning that researchers must be reflexive and responsive to the often unexpected realities of the field. Over four months in 2017, eight dancers/researchers from CRIPSiE (Collaborative Radically Integrated Performers Society in Edmonton), an integrated dance company, came together to investigate how integrated dancers practice elements of timing in rehearsal, through an arts-based, participatory process. In this paper I examine the gap between my assumptions of how research should be conducted and the reality of the field, specifically: the tension between university research ethics and the ethics of the CRIPSiE community, the differences between the value of the rehearsal process and the performance as sites of data collection, and the assumptions I had made about the necessity of a singular research question.

KEYWords Arts-based research, participatory action research, integrated dance, research ethics, disability

In the spring of 2017, seven dancer/researchers from Edmonton's integrated dance company, CRIPSiE (Collaborative Radically Integrated Performers Society in Edmonton) and I came together to research how integrated dancers practice timing in rehearsal, particularly moving fast and slow, unison movement, transitions in improvisation scores, and the coordinated timing of partnering. Integrated dance (also called mixed-abilities dance or inclusive dance) is an art form that brings together disabled' and non-disabled people to train, create, rehearse, and perform together (Benjamin, 2002). The group reflected the diversity of CRIPSiE in that of the dancer/researchers involved in the research; four identified as disabled (with a variety of impairments), two as seniors, one as hard of hearing, three as queer and one as a person of colour. We used arts-based participatory research where moving together was one of many ways of investigating our research question.

\footnotetext{
${ }^{1}$ In this article I use the language that I, and the dancer/researchers from CRIPSiE use for ourselves. We draw on the social model of disability (Shakespeare, 2006), using 'disabled people' to draw attention to the ways that people are disabled by physical space, social expectations, attitudes and public policy.
} 
I write these sentences often. I write them for grants, scholarships, and conference applications - anywhere where I need to summarize my research. I write these things and it sounds simple and complete, a modest example of arts-based research in a disability arts community. In reality, the process was messy, complex, and surprising. In particular, as I journeyed through the process with the dancers/researchers, I found I had made assumptions about the research process that I needed to re-evaluate. These assumptions highlighted differences between how I imagined the research process based on my graduate training in the University and what was valued by the community I was researching with. Specifically, I encountered: differences between the ethics of the University and CRIPSiE; differences between the importance that the dancers/researchers and I placed on performance; and, differences between how I assumed good research was designed, specifically the relationship between research question and research study design, and how the dancer/researchers related to the research question as the research/rehearsal process unfolded. Both arts-based research and participatory action research (PAR) call on researchers to critically reflect on the research process (Finley, 2011; Nygreen, 2009). While calls for reflection often center around reflexivity, critical self-evaluation of the researcher's social position and the ways researchers' social position affect the research (Berger, 2015), I believe that critical reflection on the research process as a whole is a valuable exercise. My research process included reflecting on my social position as a neurodivergent ${ }^{2}$, white, cis woman who was raised middle-class with significant access to the arts and the power dynamics inherent to my position of Co-Artistic Director of CRIPSiE. Here, I focus on my assumptions about conducting research, the reality of the research process and what I learned from the gap between the two. As such, this paper is concerned with what I learned about conducting research, rather than on the results of my research.

Arts-based research, particularly arts-based research informed by PAR, is a vital tool for researchers working with disability communities. Mertens, Sullivan, and Stace (2011) advocated that given the violence perpetuated on disability communities by academic research, researchers must find ways to share power with disability communities and to conduct research in ways that are credible and useful to members of the community. Snyder and Mitchell (2006) similarly argued that the university cannot simply divorce itself from the invasive, eugenic practices that have characterized research relations with disabled people for the past two centuries. Eugenics was the scientific and political movement that aimed to improve human genetics. Eugenic policies and practices were often twofold: they encouraged white, able-bodied people from Western Europe to reproduce, and simultaneously used marriage prohibition, institutionalization, sterilization, and death to limit the reproduction of people of colour and disabled people (Malacrida, 2015). Researchers must be accountable to the eugenic histories of universities in their relationships with disability communities (Dolmage, 2017; Snyder \& Mitchell, 2006). In arts-based research, relationality is the primary tool used to enable a collective, transformative imagining of better worlds (Conrad \& Beck, 2016; Finley, 2011), making it ideal for work in disability communities. In PAR, accountability to the community

\footnotetext{
${ }^{2}$ Neurodivergent means that my brain functions in ways that are outside dominant, socially constructed understandings of normal neurological functioning (Walker, 2014).
}

Engaged Scholar Journal: Community-Engaged Research, Teaching, and Learning 
involved is one of the guiding principles (McIntyre, 2008). As Eales and Peers (2016) pointed out, arts-based research can allow us to communicate that which cannot be captured in words, especially if words are not easily accessible to all members of the community. I further suggest that arts-based participatory research may be particularly appropriate to research within disability arts communities as these communities are familiar with their medium and skilled at finding ways to communicate with it.

Given all these reasons to do arts-based participatory research with disability arts communities, I offer my reflections on my experiences conducting arts-based participatory research with the integrated dance community of CRIPSiE. I hope my experiences can offer other researchers deeper understanding of the potential complexities and tensions of doing arts-based participatory research in disability arts communities.

\section{Participatory Action Research and Arts-Based Research}

My methodology drew upon arts-based research, particularly performance ethnography, and PAR. Arts-based research and PAR are distinct types of research that emerged as responses to the ethical questions raised by the crisis of representation (Denzin \& Lincoln, 2000) concerning researchers' relationship to the people they studied, and how researchers represented themselves, their subjects and their research. Both arts-based research and PAR share similar values of relationality and attention to power relations (Conquergood, 2013; Jordan, 2003).

Participatory action research centers relational and axiological concerns (Grant, Nelson, \& Mitchell, 2008; Nygreen, 2009). These concerns are addressed by attention to power relations, particularly power relations between the community involved in the research and the researcher (Grant, Nelson, \& Mitchell, 2008; Nygreen, 2009); by reflexive practices, particularly the practice of the researcher considering their own social location (Absolom \& Willett, 2005); by the participation of the community in every stage of the research process from determining the research question to knowledge translation (Brydon-Miller, 2008) and by a critical stance towards dominant structures and practices of the world (Chatterton, Fuller, \& Routledge, 2007; Jordan, 2003). A PAR process may unfold through multiple cycles of research and responsive action, giving the community involved the information and tools they need to create change (Nygreen, 2009). Drawing from the principles of PAR, particularly the involvement of the community in every stage of the research process and the critical stance toward dominant ways of doing and knowing, is for me, key to an ethical research engagement with a disability arts community.

Arts-based research, "is grounded ontologically in a belief that we are all, at a fundamental level, creative and aesthetic beings in inter-subjective relation with each other and our environment" and "celebrates art's potential to transform the world" (Conrad \& Beck, 2016, p. 1). The arts-based research paradigm prioritizes aesthetic creativity, relationships, and the potential of transformative change. In the search for transformation towards a better world the process of inquiry and aesthetics are related (Barone \& Eisner, 2012). Within the broad category of arts-based research I looked to performance ethnography to design this study. Performance 
ethnography uses the creation of performance and performance itself to collaboratively create knowledge (Conquergood, 2013; Denzin, 2003). Performance ethnography does not have a set process of research, but like PAR, emphasizes particular values when designing the research process. In addition to emphasizing ethical relationships with the community involved in the research, performance ethnography scholars have often emphasized the embodied nature of performance ethnography (Conquergood, 2013; Denzin, 2003; Hamera, 2011). This emphasis intends to disrupt the assumption that language is the default medium of knowledge generation and transmission, and to value knowledge generated and communicated through physical embodiment (Denzin, 2003). This emphasis on embodiment is particularly suited to research in a dance community, and especially an integrated dance community.

Given the compatibility of PAR and arts-based research to research with disability communities, it should be no surprise that research combining disability and dance, or using PAR in disability communities, is robust. Malling (2008), worked with Deaf dancers diagnosed with mental illness to explore culturally and linguistically affirmative dance therapy and creation. Kuppers's $(2007,2011)$ extensive body of research ranges from research projects involving community dance to writing collaborations (Kuppers \& Marcus, 2009). Kuppers (2011) documented the work of the Olimpias, a disability arts collective who explored performance as a place where disability cultures are created. Eales and Peers (2017) explore materiality and the slippery line between disabled and non-disabled through performance art and writing. Peers' use of their wheelchair made their disability obvious while Eales' lack of mobility tool means that they are read as non-disabled. Eales (2013) worked with iDance Edmonton, the group that would become CRIPSiE, to investigate understandings of social justice in an integrated or mixed-abilities dance community.

Moving beyond arts-based methodologies researchers have used dance settings to investigate experiences of inclusion for children with disabilities (Goodwin, Kohn, \& Kuhnle, 2004) and to investigate how children understood disability and difference (Zitomer \& Reid, 2011). Integrated dance performance has been read as a cultural text for its attitudes towards disability (Cooper Albright, 1997; Sherlock, 1996; Smith, 2005). Irving \& Giles (2001) conducted an ethnography with a professional integrated dance company to explore how dancers navigated dominant discourses of disability and dance. Of all these examples, only the research of Irving and Giles (2001) and Eales (2013) was located within professional or professionalizing integrated dance companies, and only Eales (2013) uses arts-based methods. Although arts-based research and PAR commonly work with marginalized communities, there is limited arts-based research done with integrated dance communities such as CRIPSiE.

\section{Study Context and the Study}

CRIPSiE is an integrated arts company focusing on dance and video in Edmonton. It was founded by Lindsay Eales in 2005 as iDance Edmonton and incorporated as CRIPSiE in 2013. Currently, I hold the title of Co-Artistic Director of CRIPSiE along with Lindsay Eales. This means that I work with my Co-Artistic Director, the artistic associates and the board to develop and deliver artistic and administrative projects. I also teach, choreograph, and 
dance on a regular basis. While I am neurodivergent, my disability experiences do not erase my position of power in CRIPSiE, or my position of power as a researcher working in a disability community. CRIPSiE works with artists with a wide diversity of bodies, minds, and experiences, aiming to "challenge dominant stories of disability and oppression through highquality crip and mad art" ('About us', n.d.). The dominant stories of disability that CRIPSiE challenges include those of pity and inspiration, stories that reduce disability to a tragedy to be overcome (Kelly \& Orsini, 2016). Crip and mad are pejorative words reclaimed by disability communities as ways to describe new orientations to disability and mental illness. Crip and mad imagine what it is to desire disability (McRuer, 2006) and to desire what disability disrupts (Fritsch, 2013). In doing so, CRIPSiE reframes disability, impairment, and other experiences of marginalization as full of generative, creative potential.

CRIPSiE has positioned itself as a "professionalizing" (Acton \& Eales, 2015, p. 27) arts company to granting agencies and presenting organizations. It performs in professional and pre-professional festivals, collaborates with arts professionals, and is supported by municipal, provincial, and federal funding intended both for professional and community arts organizations. Most of the artists, however, have not had access to professional arts training (Acton, 2017). Like many Canadian integrated and disability arts companies, CRIPSiE struggles to negotiate the standards of professionalism in the arts world while maintaining an emphasis on accessibility (Irving \& Giles, 2011; Johnston, 2012). It is out of this desire for accessibility that my research arose.

The physical, administrative, and social barriers to disabled people's full inclusion in society are well documented (Shakespeare, 2006). Critical disability scholars, however, are only beginning to think through how dominant understandings and practices of time exclude people experiencing disability from full participation in society (Kafer, 2013). Within integrated dance, Irving \& Giles (2011) noted elements of timing in dance, for example extremes of fast and slow and the demands of unison movement, as particularly challenging to an integrated dance company making the shift to more professional dance work. For CRIPSiE, timing seemed to be an ongoing point of negotiation. In $A$ New Constellation: A Dancumentary, which followed CRIPSiE through the creation of a dance piece, Iris remembered joining CRIPSiE for the first time (Duval, Eales, Peers, \& Ulanicki, 2013). She said:

So for fifteen years I did without dancing, and then I walked in and I heard the words, five, six, seven, eight, and it's like a shot of adrenaline, and I thought: "I'm home, I'm home, I'm home". I love it.

For Iris, precise counts were something wonderful that connected her to her previous experiences of dance. Yet other moments in the documentary gave me clues that precise timing is not always an easy, joyful thing. For instance Alex said, "You have to listen to the music. And Lindsay's, Lindsay's music is tricky too!” (Duval, Eales, Peers, \& Ulanicki, 2013). Or when Julie said, "I think a challenge for me is to find my timing isn't what I think it should be” (Duval, Eales, Peers, \& Ulanicki, 2013). These comments resonated with my own lived 
experiences as a neurodivergent dancer whose ability to perform timing in normative and integrated dance spaces is deeply affected by auditory processing differences and a unique sense of time (Molenaar-Kumper, 2002).

I did not, however, want to assume that other dancers in CRIPSiE shared my experiences. Before embarking on this research I informally consulted with members of CRIPSiE to determine that there was interest in examining practices of timing within the community. I had conversations with five different community members, two of whom joined the research project, who agreed to that practices of timing were an area that CRIPSiE had not thought critically about yet and therefore were worth researching. One community member, who did not ultimately take part in the research project, suggested to me that our practices of timing assumed able-bodiedness and that this research was urgently needed to transform our current practices.

Denzin and Lincoln (2000) described the arts-based researcher as a bricoleur, who "uses the aesthetic and material tools of his or her craft, deploying whatever strategies, methods, or empirical materials are at hand. If new tools or techniques have to be invented, or pieced together, then the researcher will do this" (p. 4). As Denzin and Lincoln (2000) suggested, I drew upon my tools as an integrated dancer and choreographer, informed by PAR and performance ethnography with particular attention to the rehearsal process as a site of knowledge creation. My tools as an integrated dance and choreographer arise from a decade spent in the CRIPSiE community and over fifteen years of dance training and teaching in normative settings.

I applied for research ethics approval from the University of Alberta's Research Ethics Office (REO) and received it on February $2^{\text {nd }}, 2017$. In addition, this study also passed CRIPSiE's research approval process in which potential researchers must submit answers to five questions for the study to be evaluated by a group of artistic associates for it's fit with CRIPSiE's values. I then drew upon my connections in CRIPSiE for convenience sampling (Patton, 2002). CRIPSiE's artists are diverse, with some identifying variously as seniors, queer, racialized, mad, hard of hearing, and disabled (Acton, Chodan \& Peers, 2016). The sole criterion for this study was experience in integrated dance since experience in integrated dance meant that dancers would have some experience with timing in the rehearsal process. I recruited seven dancers: Brooke, Chris, Sara, Robert, Sheena, Iris, and Alexis. These dancer/ researchers reflected the diversity of CRIPSiE, since all of the facets of identity I mention above were reflected in this group. All the dancer/researchers opted to be identified by their own names as integrated dance in Canada is a small community and anonymity would likely be impossible.

We met for fifteen rehearsals, two hours each, for a total of thirty hours. Consistent with CRIPSiE's current rehearsal practices, the rehearsals were closed to people not involved in the rehearsal/research process. On the first day we met I provided the dancers/researchers with the research question, but asked them to brainstorm around timing, allowing them to set the research priorities within the broad topic of timing. At the end of each rehearsal I would summarize for the dancer/researchers what we had and had not explored that day and ask for input on the plan for the next rehearsal. These measures meant that the dancer/researchers

Engaged Scholar Journal: Community-Engaged Research, Teaching, and Learning 
controlled both the research and artistic process, consistent with the principles of PAR and arts-based research. I voice recorded rehearsals, video recorded movement phrases, and wrote field notes after every rehearsal.

Despite the careful planning that went into this process I still encountered significant tensions that revealed assumptions I had made about the research process. I now turn to a discussion of the first of the tensions I experienced; the difference between the research ethics of the university and the community ethics of CRIPSiE.

\section{University Ethics and Community Ethics}

Tensions between community ethics and University ethics processes are common in community-based work (Kendall, Nguyen, Glick, \& Seal, 2017). Although the University of Alberta REO was responsive to the needs of this project, competing assumptions emerged over where the ethical authority lay for this project. The REO articulated the need for the university to serve the community through the discovery and dissemination of research. In addition, it followed the Tri-Agency Framework, and articulated that research ethics review, "is geared towards protecting participants by minimizing the harms or risk to which they are exposed" ('Research Ethics', n.d.). The research ethics application form reflected this, asking me to provide an assessment of the risks that participants may encounter in their research.

CRIPSiE itself has a robust ethical review process that this project passed in addition to the REO. The requirements of an application to do research with CRIPSiE revealed a very different set of concerns that those of the research ethics office. The questions were:

1. How much time will be required of community members?

2. Will members be paid for their time and expertise? How will this research benefit the community?

3. What kinds of ethical guidelines are you considering?

4. Have you ever danced or participated in this community? Other communities like it?

5. How will the results be made accessible to the community?

('CRIPSiE Research Application, n.d.)

These questions revealed a concern with compensating marginalized members of the community for their time and energy and how the results would be made available and accessible to the community. CRIPSiE's research application questions also revealed a preference for insider researchers, that is, researchers who have ties to CRIPSiE or other communities like CRIPSiE (Krpitchenko \& Voloder, 2014). The research ethics that informed CRIPSiE's application to do research in the community were similar to the concerns of artsbased research and PAR that prioritize the community and its values in the research process.

In this list of research questions, the potential researcher was asked directly if they plan to pay CRIPSiE artists. Paying participants is of particular concern for research in disability communities as Snyder and Mitchell (2006) identified, "the inexhaustible research machine" 
(p. 187) that exploits disabled peoples' time and energies as a particular threat to the wellbeing of disabled people. Researchers have identified not paying, or minimally paying, research participants as good practice to avoid coercing low income participants (Polascek, Boardman, \& McCann, 2016). This is, however, contested by researchers who argued that minimally paying or not paying research participants creates a situation of "mutually beneficial consensual exploitation" (Largent \& Fernandez Lynch, 2017, p. 7) that should be of ethical concern to researchers. For Largent and Fernandez Lynch the fact that the participants have consented to the research and receive benefit from the research process, often in the form of feeling like they are contributing to important knowledge creation, did not make not paying research participants less exploitative.

Not paying dancers for their labour was not considered ethical within CRIPSiE (Eales, 2013). Indeed, one of the driving forces behind the formation of CRIPSiE was a desire to treat, and pay, disabled dancers as artists (Eales, 2013). I would also note that within the broader Edmonton arts context choosing not to pay artists is considered less than ideal. There is a sense that arts work is under-valued and paying artists values their time and skill. The cultural context of CRIPSiE, the broader Edmonton arts scene, and research into the challenges facing artists and disabled people all suggested that I should have paid my participants.

Unfortunately, concerns about the Research Ethics Office's objection to paying participants and the timing of arts granting cycles meant that I was unable to pay the dancers/researchers. I clearly communicated in recruitment and at the first rehearsal that working on this artistic research process was not a paid opportunity. All the dancers/researchers involved chose to engage anyway. Ultimately, I feel that the dancers/researchers did receive benefit from being part of this research project. Many of them repeatedly expressed that they found significant meaning in being involved in a collaborative research/rehearsal process and tackling questions that had meaning for the community together. For a few of them the opportunity to take on a collaborative, choreographic role where they were responsible for generating all the movement and making choreographic choices was novel and deeply important to them. I am troubled, however, by the expectation that artists or disabled people, especially disabled artists, will engage in research, including arts-based participatory research, that will likely require substantial time and effort, for minimal or no pay. In addition, I wonder if unpaid research instead of paid creation was the norm for CRIPSiE if the artists involved would have still found these experiences meaningful. I made the choice to go ahead with the research without funding to pay the dancers/researchers, but I still feel uneasy about the choice.

This was not the only time that the expectations of CRIPSiE and the university research clashed. Although these moments were not about major ethical conflicts, such as the question of paying participants, they revealed different assumptions about where the ethical authority of the project was located. Early in the ethics process the REO suggested that I change my recruitment procedure to navigate my position of power as Co-Artistic Director of CRIPSiE and avoid coercion. Initially I had suggested that I would email potential dancers/researchers directly to inform them of the study. The reviewer suggested that instead, I should provide my supervisors with contact information and one of my supervisors would email potential 
dancers/researchers. When I took this change to CRIPSiE's research review process it was roundly rejected. The artistic associates were not comfortable with someone outside of the community, who artists had never met, emailing them to recruit them for a study. They suggested instead that my Co-Artistic Director email potential dancers/researchers.

This change was accepted by the REO, but reveals different assumptions about where the moral authority of the project was located. For the University, my supervisory team would naturally be involved in helping me navigate ethical sticking points. For CRIPSiE's artistic associates, my supervisory team was outside the relationship of trust that was being built with me as a researcher. Even though I had been clear that my supervisors would have access to all my data, my supervisors' direct involvement felt like too much to the artistic associates reviewing my study.

Another similar moment occurred when the dancers/researchers decided on the second to last rehearsal that they did not want to hold a focus group to reflect on the overall research process. Because of conflicting summer schedules the first time that everyone would be able to get together to hold a focus group would have been in mid-September, which left a gap of two and a half months between the final rehearsal and the focus group. The dancer/researchers decided this was too long and proposed that I send them my focus group questions to answer, individually, over email.

Changing from a focus group to an email interview, however, required me to submit an amendment to the REO. I submitted this request on June 28, 2017 and received permission for this change on July 20, 2017. Even this brief gap was baffling to a few of the dancers/ researchers who asked me why I hadn't sent out the email interview immediately. There was confusion about why I would need to ask permission-after all they had unanimously told me to make this change to the research plan. For the dancers/researchers, the authority and ownership over the research rested with them, not the university.

The difficulty of anticipating how a participatory project will unfold is not unusual (Dyer \& Löytönen, 2012). In retrospect, I should have anticipated possible changes to the research plan and taken more time at the start of the process to educate the dancers/researchers on the role of the REO and why it exists. I had been careful to outline the process and requirements of a $\mathrm{PhD}$ to them, particularly that it would be a long time before they were asked for feedback on my dissertation or any articles that might emerge from this research. I had not taken the same care to outline the role of the REO. A better explanation of the role of the REO to them would have given the dancers/researchers valuable insight and context into how the university imagines and conducts ethical research without dismissing the ways of researching and the ethics already present in the CRIPSiE community.

I take from these moments of tension that researchers engaging in community-engaged scholarship, particularly with communities like CRIPSiE that have a strongly developed sense of research ethics, must be prepared to navigate the sometimes significant divide between the ethical assumptions of the community and the University. In addition, I suggest that researchers must be prepared to explain and advocate for the ethics of the community to the university, and the ethics of the university to the community where appropriate. 


\section{Rehearsal and Performance}

When I was designing this study I did not anticipate the differences between the ethics of the university and the ethics of CRIPSiE_- I also made another significant error about the importance and relationship of rehearsal to performance. When I designed this study I deliberately excluded performance in order to manage the volume of data. Between field notes, transcripts of rehearsals and video of movement sequences there seemed to be more than enough data. At the time, my experiences as a researcher and an artist suggested that the rehearsal was far more significant to creating knowledge than performance. As a researcher, when I read arts-based research I often find myself craving deeper descriptions of the rehearsal. As an artist, I find the most meaning making occurs for me in rehearsal as opposed to performance. It seemed reasonable to exclude performance from the research process. In practice, however, excluding performance proved impossible. The combination of CRIPSiE's existence within the broader Edmonton arts context, and the meaning and significance that the dancer/researchers placed on performance meant that performance shaped the way the rehearsal process unfolded and was a significant event in and of itself.

Just a week before I started the rehearsal/research process CRIPSiE was offered a performance slot with Nextfest, Edmonton's large emerging artists festival that takes place each year in June. I felt that I needed to bring the opportunity to the dancers/researchers. My commitment to a participatory research process meant I should not predetermine the research process, but rather bring the dancers/researchers options for how the research process might unfold. In addition, Nextfest was a paid opportunity. As mentioned above, I felt ethically uneasy with not paying dancers/researchers. While I could not pay the dancers/researchers for the rehearsal/research process, the exemption of performance from the research process meant that CRIPSiE could pay dancers for the performance opportunity.

There was also a particular symbolic weight to this performance. Up until 2017 the dance performances at Nextfest had taken place in a physically inaccessible theatre. CRIPSiE had taken part twice before in Nextfest, once presenting a piece of site specific theatre in a church, and once presenting a piece that pointed out the inaccessibility of the theatre the dance performances were presented in. Having CRIPSiE perform the first year that Nextfest's dance program was in an accessible theatre seemed like an important, symbolic gesture. I brought the possibility to the dancers/researchers and after some discussion about how a performance date would change the research/rehearsal experience, we committed to the performance.

Once we accepted the performance, the relationship of the performance to the rehearsal process was evident in almost every rehearsal. The date of the performance shaped our attitudes to what we needed to accomplish at rehearsal. Alexis, looking back at the rehearsal process said:

And I think we all collectively, around that time, were like, okay this is where we're at, we're not going to like, keep adding or taking away, we just understood that. But you know, had the performance been in August we would have still been working on things right now. 
The performance date forced us to grapple with questions of what was good integrated dance? What were we prepared to put in front of an audience? The pressure of an upcoming performance pushed the process from exploration and forced a kind of analysis on the dancers/researchers where we were forced to evaluate what we were prepared to reveal to an audience. This deepened the work in particular ways, making it more critical and analytic earlier in the research/rehearsal process than it might have been had we not had a performance date.

Most significantly, I learned that performance was deeply, personally important to the dancers/researchers. Our research/rehearsal period extended past the performance dates and when we returned to rehearsal following the performance it was clear to me that I had radically underestimated the importance of performance. Most of that rehearsal we spent talking about the experience of the performances, how the improvisation and the timing in the improvisation changed from night to night, and analyzing friends and family members' reactions to the piece. These conversations were deep and rich, producing invaluable insights into how we understood virtuosity and skill in integrated dance, and how we approach learning timing and other skills in the rehearsal process. The opportunity to perform was deeply meaningful to the dancers/researchers and provided significant insights into our research.

When I entered this research process I underestimated how important performance would be to the research. I was more concerned with managing the volume of data that would be generated from this study than with the data, and the personal meaning, the opportunity to perform could generate. Ultimately, I was lucky. I was lucky that the dance program at Nextfest had moved into an accessible theatre, that programmers were interested and invested in having CRIPSiE perform and that the dancers/researchers were interested in the opportunity. While I cannot predict where the research would have gone without the opportunity to perform, there is a richness to the data we collected that would not have been there without it. Based on my experiences I suggest that arts-based researchers working artistic mediums that include performance such as music, theatre, and dance should carefully negotiate the role and significance of performance in the research process with their co-researchers.

\section{Multiple Research Questions}

The other major area of tension I experienced was the research question and the design of the study. In the social science research process in which I had been trained, it is important to define as much of the study, and indeed, know as much as possible before you enter the field. While Markula and Silk (2011) acknowledged that qualitative research is necessarily messy and non-linear, they also advised that the researcher begin from a clear research question to enable the selection of appropriate, "paradigmatic approach, theoretical concepts and appropriate methodological practice(s)” (p. 61). Markula and Silk (2011) suggested that this approach - starting from the question and basing all subsequent research design choices off the question_-provides the most potential for meaningful results. It was this approach, driven by a singular, specific research question that I had absorbed as the right way to do research.

I acknowledge that my research is not wholly consistent with this principle. The question, how do integrated dancers practice timing in rehearsal, might have been better addressed 
by a participant observation study, rather than by arts-based participatory research. I felt, however, that the collaborative orientation offered by arts-based participatory research was more appropriate to working with a group of marginalized people from populations who are often under surveillance (Feely, 2016; Hilton, 2017). I chose to prioritize ethics over a clear connection between the question being asked and the methodology used ${ }^{3}$. The choice to address my research question through a methodology that was not clearly linked to the question turned out to offer myself and the dancers/researchers the freedom to acknowledge the multiple questions and desires in the research/rehearsal process.

Acknowledging multiple research questions and desires helped me navigate an ethical concern that I had not adequately prepared for. Even though it is obvious in retrospect, given my long history in the community, I had not taken into account the degree to which the dancers/researchers were invested in my success as a graduate student researcher. In early rehearsals, they often asked, "Are you getting what you need?". I became worried that they were more invested in me being successful than they were in making the research/rehearsal process fit their needs and desires. Before embarking on the rehearsal/research process I had reflected on my position of power as CRIPSiE's Co-Artistic Director and as a researcher. I had designed recruitment information to make it clear that involvement in the project would have no influence on future work with CRIPSiE. I had resolved to write field notes to encourage reflexivity around power dynamics in rehearsal and thought about how to create rehearsal plans that put the dancers/researchers in charge of decision-making. I had not anticipated friendship as a dynamic that I would need to think through and be reflexive about. In response to these questions about what I needed, I reminded the dancers/researchers that in arts-based participatory research it is important for the community to shape the research according to their needs. The research design also meant that I was able to reassure them that the research question I had started with, how do integrated dancers practice timing in rehearsal, would be answered regardless of where they chose to take the research. This seemed to reassure them and allow them to follow their curiosity, including exploring topics such as the relativity of time near black holes that were deeply important to the dancers/researchers but did not directly address my original research question.

It became obvious to me as the rehearsal/research process went on that the rehearsal hall held a number of questions and desires and these questions and desires changed day to day. Some days, dancers/researchers were concerned with asking, what are the conditions that create the possibilities of flow? Sara, in particular, returned again and again to the question of flow, asking, "I've always been observing when do I reach the flow state, like how many minutes in, with whom, what was the transition to the flow state"? Other days, the dancers/ researchers asked, how do I embody extremes of fast and slow? One day, Chris was invested in the question of how embodying extremes of fast and slow shifted his perceptions of the space we move in, his body, and the relationship between the space and his body. Later in the

${ }^{3}$ If I am being entirely truthful, this decision was also about desire. I returned to graduate school because I fell in love with the idea of arts-based research and desperately wanted to experience doing arts-based research. Barone and Eisner (2012) warn researchers against this... and I still followed my desires.

Engaged Scholar Journal: Community-Engaged Research, Teaching, and Learning 
process we often asked, how do we embody the movement of celestial bodies in ways that honor the meaning I find in their movements? How do we create a piece of dance where the audience will read clear aesthetic choices that celebrate the ways non-normative bodies and minds move as opposed to failure caused by impairment?

These are just a few of the many questions that emerged from the room. It is important to note that these questions were not shared by all of the dancers/researchers. These questions reflect different paradigmatic orientations and different assumptions about disability and art. If we were to investigate each of these questions following the principle that the research question determines the paradigmatic, theoretical and methodological approaches, they would require separate and very different research studies. This diversity of questions and desires is familiar to me as an artist. For me, assisting a group of artists in sorting through curiosities and desires to arrive at a cohesive piece of art is at the heart of the work of a facilitator in performer-created performance. It is work that I take for granted in the rehearsal process as an artist. Entering this research/rehearsal process, however, I was so focused on doing research well that I did not account for this dynamic.

Reflecting on this dynamic, it is clear that this is actually a strength of arts-based participatory research. Regardless of paradigmatic orientation or methodology, participants in research enter into research studies for their own reasons. These reasons may include investigating questions that are very different from the researcher(s). Including many people in a research process means they will bring different interests, experiences, questions, and desires to the process. Inclusivity and accountability, particularly in the case of doing research in disability communities, may mean that the research needs to be porous enough to hold these different desires together. I initially thought my research design was flawed because it did not directly answer my research question. The indirect nature of the design, however, allowed me to navigate my concerns that the dancer/researchers might be prioritizing my success as a graduate student researcher over their own needs and desires by allowing for the presence of many research questions and agendas. This allowed me, as a facilitator and researcher, to be attentive and responsive to the many questions that the dancers/researchers were interested in investigating and how those questions changed from day to day. While my research question might have been more directly answered by an observational study, the indirect nature of my study allowed for this multiplicity of research questions and desires to be explicit in the room. In doing this research we proliferated questions and paradigms, just as Barone and Eisner (2012) called on arts-based researchers to do. In future, as a researcher, I will be attentive to the internal consistency of my research design but will also continue to try to make space for the proliferation of questions and interests that I suspect are inherent and vitally important to arts-based participatory research.

\section{Conclusion}

I drew on the methodologies of arts-based research and PAR to design this study, seeking an ethical relationship with the community and individuals I studied with. Both these methodologies value critical reflection as a tool to deepen the researcher's accountability and 
engagement with their community. Here, I have tried to be reflexive about the research process itself, leading me to examine the tensions I experienced between my assumptions of how the research process should work and how it unfolded in the field. Sometimes these tensions were caused by my own assumptions about how research should work. Some, like the tensions between the ethics of the University REO and the ethics of CRIPSiE reflect larger structural concerns.

Barone and Eisner (2012) wrote of arts-based research:

The utility of this sort of research is thereby based on its capacity to fulfill a second important human need. This is indeed a need for surprise, for the kind of re-creation that follows from openness to the possibilities of alternative perspectives on the world. (p. 4)

If some of the vitality and importance of arts-based research is in its capacity to surprise, then this project was successful. It surprised me, forcing myself to confront conflicting ethical points of view, to question the relationship of rehearsal, performance and research in artsbased research, and to recognize the multiplicity of research questions that were present in the rehearsal hall. I reflect on these moments of tension and discovery, looking for the ways I can do better in future arts-based participatory research processes and best serve the communities with whom I will work.

\section{About the Author}

Kelsie Acton (corresponding author) is a neurodivergent $\mathrm{PhD}$ candidate, dancer, and choreographer. Her SSHRC funded dissertation research investigates access intimacy and timing in an integrated dance rehearsal process. Her choreography has been presented by CRIPSiE, Good Women Dance Collective, Expanse Movement Arts Festival and Flux City. Email: klacton@ ualberta.ca

\section{References}

'About Us' (n.d.). CRIPSiE. Retrieved from: www.cripsie.ca

Absolon, K., \& Willett, C. (2005). Putting ourselves forward: Location in Aboriginal research. In L. Brown \& S. Strega (Eds.), Research as resistance: Critical, indigenous, and anti-oppressive approaches (pp. 97-126). Toronto, ON: Canadian Scholars' Press.

Engaged Scholar Journal: Community-Engaged Research, Teaching, and Learning 
Acton, K. (2017) 2017 Organizational funding grant for CRIPSiE (unpublished grant application to the Edmonton Arts Council, Organizational Funding Stream). Edmonton, AB: CRIPSiE.

Acton, K., Chodan, S., \& Peers, D. (2016) Organizational development grant for CRIPSiE (unpublished grant application to the Canada Council for the Arts Equity Stream). Edmonton, AB: CRIPSiE.

Acton, K., \& Eales, L. (2015). Production and development of Deconstruction Site, an evening of integrated dance (unpublished grant application to the Alberta Foundation for the Arts). Edmonton, AB: CRIPSiE.

Benjamin, A. (2002). Making an entrance: Theory and practice for disabled and non-disabled dancers. London, UK: Routledge.

Berger, R. (2015). Now I see it, now I don't: Researcher's position and reflexivity in qualitative research. Qualitative Research, 15(2), 219-234.

Barone, T., \& Eisner, E. W. (2012). Arts based research. Los Angeles, CA: SAGE.

Brydon-Miller M. (2008). Ethics and action: Research deepening our commitment to principles of social justice and redefining systems of democratic practice. In P. Reason \& H. Bradbury (Eds.), The Sage handbook of action research ( $2^{\text {nd }}$ ed., pp. 199-210). Thousand Oaks, CA: Sage.

Chatterton, P., Fuller, D. \& Routledge, P. (2007). Relating action to activism: Theoretical and methodological reflections. In S. Kindon, R. Pain, \& M. Kesby (Eds.), Participatory action research approaches and methods: Connecting people, participation and place (pp. 216-222). New York, NY: Routledge.

Conquergood, L. D. (2013). Cultural struggles: Performance, ethnography, praxis. Ann Arbor, MI: University of Michigan Press.

Conrad, D., \& Beck, J. (2015). Towards articulating an arts-based research paradigm: Growing deeper. UNESCO Observatory Multi-disciplinary Journal in Arts, 5(1), 1-26.

Cooper Albright, A. (1997). Choreographing difference: The body and identity in contemporary dance. Middletown, CN: Wesleyan University.

CRIPSiE (n.d.) CRIPSiE research application. Edmonton, AB: author unknown.

Denzin, N. K. (2003). Performance ethnography: Critical pedagogy and the politics of culture. Thousand Oaks, CA: Sage.

Denzin, N. K., \& Lincoln, Y. S. (2000). Introduction: The discipline and practice of qualitative research. In N.K. Denzin and Y.S. Lincoln (Eds.) Handbook of qualitative research, $2^{\text {nd }}$ ed., pp. 1-20). Thousand Oaks, CA: Sage.

Dolmage, J. (2017) Academic ableism: Disability and higher education. Ann Arbor, MI: University of Michigan.

DuVal, J., Eales, L., Peers, D., Ulanicki, R. (Producers). (2013) New constellation. [videorecording] : a danceumentary. Edmonton, AB: CRIPSiE.

Dyer, B., \& Löytönen, T. (2012). Engaging dialogue: Co-creating communities of collaborative inquiry. Research In Dance Education, 13(1), 121-147.

Eales, L. (2013). (Dis)quiet in the peanut gallery: A transformative performance ethnography on integrated dance. (Unpublished masters' thesis). University of Alberta, Edmonton. Retrieved from: http:// login.ezproxy.library.ualberta.ca/login?url=http:// search.ebscohost.com/login.aspx?direc $\mathrm{t}=$ true $\& \mathrm{db}=\mathrm{cat} 03710 \mathrm{a} \& \mathrm{AN}=$ alb.6504280\&site=eds-live\&scope $=$ site; http:/ / hdl.handle. net/10402/era.33977 
Eales, L., \& Peers, D. (2016). Moving adapted physical activity: The possibilities of arts-based research. Quest, 68, 55-68.

Feely, M. (2016). Sexual surveillance and control in a community-based intellectual disability service. Sexualities, 19(5/6), 725-750.

Finley, S. (2011). Arts based inquiry: Performing revolutionary pedagogy. In N. K. Denzin \& Y. S. Lincoln (Eds.), The Sage handbook of qualitative research (4 ${ }^{\text {th }}$ ed., pp. 681-694). Thousand Oaks, CA: Sage.

Fritsch, K. (2013). On the negative possibility of suffering: Adorno, feminist philosophy, and the transfigured crip to come. Disability Studies Quarterly, 33(4).

Goodwin, D. L., Krohn, J., \& Kuhnle, A. (2004). Beyond the wheelchair: The experience of dance. Adapted Physical Activity Quarterly, 21, 229-248.

Grant, J., Nelson, G. \& Mitchell, T. (2008). Negotiating the challenges of participatory action research: Relationships, power, participation, change and credibility. In P. Reason \& H. Bradbury (Eds.), The Sage handbook of action research (pp. 588-601). Thousand Oaks, CA: Sage.

Hamera, J. (2011). Performance ethnography. In N. K. Denzin \& Y. S. Lincoln (Eds.), The Sage handbook of qualitative research ( ${ }^{\text {th }}$ ed., pp. 317-330). Thousand Oaks, CA: Sage.

Hilton, L. J. (2017). Avonte's law: Autism, wandering, and the racial surveillance of neurological difference. African American Review, 50(2), 221-235.

Irving, H. R., \& Giles, A. R. (2011). A dance revolution? Responding to dominant discourses in contemporary integrated dance. Leisure/Loisir: Journal of the Canadian Association for Leisure Studies, 35, 371-390.

Johnston, K. (2012). Stage turns: Canadian disability theatre. Montreal, QC: McGill-Queen's University.

Jordan, S. (2003). Who stole my methodology? Co-opting PAR. Globalization, Societies and Education, 1, 185-200.

Kafer, A. (2013) Feminist, queer, crip. Bloomington, IN: Indiana University.

Kelly, C. \& Orsini, M. (2016) Introduction: Mobilizing metaphor. In C. Kelly \& M. Orsini (Eds.), Mobilizing metaphor: Art, culture and disability activism in Canada (pp. 3-21). Vancouver, BC: UBC.

Kendall, C., Nguyen, A. L., Glick, J. \& Seal, D. (2017) Research methods and community-based participatory research. In S. S. Couglin, S.A. Smith \& M. E. Fernandez (Eds.), Handbook of community-based participatory research (pp. 21-38). New York, NY: Oxford University.

Krpitchenko, L. \& Voloder, L. (2014) Insider research method: The significance of identities in the field. London, UK: Sage.

Kuppers, P. (2007) The scar of visibility: medical performances and contemporary art. Minneapolis, MN: University of Minnesota.

Kuppers, P. (2011) Disability culture and community performance: Find a strange and twisted shape. Houndsmill, Basingstoke, UK: Palgrave Macmillan.

Kuppers, P., \& Marcus, N. (2009). Contact/disability performance: An essay constructed between Petra Kuppers and Neil Marcus. Research in Drama Education, 14(1), 141-155.

Largent, E., \& Fernandez Lynch, H. (2017). Paying research participants: The outsized influence of "undue influence". IRB: Ethics \& Human Research, 39(4), 1-9.

Malacrida, C. (2015) A special hell: Institutional life in Alberta's engenic years. Toronto, ON: University of Toronto. 
Markula, P., \& Silk, M. L. (2011). Qualitative research for physical culture. [electronic resource]. New York, NY: Palgrave Macmillan. Retrieved from: https://link-springer-com.login.ezproxy.library. ualberta.ca/book/10.1057\%2F9780230305632

McIntyre, A. (2008). Participatory action research. Thousand Oaks, CA: Sage.

McRuer, R. (2006). Crip theory: Cultural signs of queerness and disability. New York, NY: New York University.

Mertens, D.M., Sullivan, M. \& Stace, H. (2011) Disability communities: Transformative research for social justice. In N.K. Denzin \& Y.S. Lincoln (Eds.), The Sage handbook of qualitative research (4 ${ }^{\text {th }}$ ed., pp. 227-241). Thousand Oaks, CA: Sage.

Molenaar-Klumper, M. (2002) Non-verbal learning disabilities, characteristics, diagnosis and treatment within an educational setting. London, UK: Jessica Kingsley.

Nygreen, K. (2009). Critical dilemmas in PAR: Toward a new theory of engaged research for social change. Social Justice, 36(4), 14-35.

Patton, M. Q. (2002). Qualitative research \& evaluation methods ( $3^{\text {rd }}$ ed.). Thousand Oaks, CA: Sage.

Peers, D., \& Eales, L. (2017). Moving materiality: People, tools, and this thing called disability. Art/ Research International, 2(2), 101-125.

Polacsek, M., Boardman, G., \& McCann, T. V. (2017). Paying patient and caregiver research participants: putting theory into practice. Journal Of Advanced Nursing, 73(4), 847-856.

'Research Ethics (n.d.) University of Alberta. Retrieved from: http://www.reo.ualberta.ca/en/ResearchEthics.aspx

Shakespeare, T. (2006). Disability rights and wrongs. London, UK: Routledge.

Sherlock, J. (1996). Dance and the culture of the body: Where is the grotesque? Women's Studies International Forum, 19, 525-533.

Smith, O. (2005). Shifting Apollo's frame: Challenging the body aesthetic in theatre dance. In C. Sandahl \& P. Auslander (Eds.), Bodies in commotion: Disability and performance (pp. 73-85). Ann Arbor, MI: University of Michigan.

Snyder, S. L., \& Mitchell, D. T. (2006). Cultural locations of disability. Chicago, IL: University of Chicago.

Walker, N. (2014) Neurodiversity: Some basic terms and definitions. Neurocosmopolitanism, Nick Walker's Notes on Neurodiversity, Autism and Cognitive Liberty. Retrieved from: http:/ / neurocosmopolitanism.com/neurodiversity-some-basic-terms-definitions/

Zitomer, M. R., \& Reid, G. (2011). To be or not to be - able to dance: Integrated dance and children's perceptions of dance ability and disability. Research in Dance Education, 12, 137-156. 